\title{
Qualidade de grãos de milho armazenados em silos bolsa ${ }^{1}$
}

\author{
Quality of corn grain stored in silo bags
}

\author{
André Rodrigues da Costa ${ }^{2}$, Lêda Rita D’Antonino Faroni ${ }^{3}$, Ernandes Rodrigues de Alencar ${ }^{4 *}$, Marta Cristina \\ Silva Carvalho ${ }^{5}$ Laíne Garcia Ferreira ${ }^{6}$
}

\begin{abstract}
Resumo - A utilização de bolsas seladas hermeticamente é uma alternativa aos métodos tradicionais de armazenagem de grãos em nível de fazenda. Em vista disso, objetivou-se com este trabalho avaliar a qualidade de milho armazenado hermeticamente em silos bolsa. O produto, com teores de água de 14,5 e 18,0\% b.u, foi acondicionado em mini-bolsas devidamente seladas nas temperaturas de $25 ; 30$ e $35^{\circ} \mathrm{C}$. Foram realizadas análises de teor de água, de classificação dos grãos, de massa específica aparente, de percentual de germinação e de condutividade elétrica, no início do armazenamento e após 30; 60; 90; 135 e 180 dias. Verificou-se que não houve variação do teor de água dos grãos de milho armazenados nos silos bolsa. Os grãos de milho foram classificados como Tipo 1 ao longo do período de armazenamento, exceto para os com $18,0 \%$ (b.u.) de teor de água na temperatura de $35^{\circ} \mathrm{C}$. Não houve decréscimo significativo da massa especifica aparente do produto ao longo do armazenamento. Em geral, ocorreu decréscimo do percentual de germinação dos grãos de milho armazenados úmidos e secos e acréscimo da condutividade elétrica da solução que continha os grãos, exceto para os armazenados com $14,5 \%$ nas temperaturas de 25 e $30^{\circ} \mathrm{C}$. Conclui-se que é possível armazenar milho em silos bolsa, durante 180 dias, grãos com teor de água de $14,5 \%$ (b.u.) nas temperaturas de $25 ; 30$ e $35^{\circ} \mathrm{C}$ e grãos com teor de água de $18,0 \%$ por 180 dias nas temperaturas de 25 e $30^{\circ} \mathrm{C}$.
\end{abstract}

Palavras-chave - Armazenamento hermético. Qualidade fisiológica. Classificação.

\begin{abstract}
Airtight storage in sealed bags provides an alternative to traditional methods for on-farm grain storage. The objective of this work was therefore to evaluate the quality of corn stored in airtight sealed bags. Grain with moisture content (m.c.) of about 14.5 and $18.0 \%$ (w.b.) was properly stored in sealed mini-bags at $25 ; 30$; and $35{ }^{\circ} \mathrm{C}$. Analyses included moisture content, grain classification, apparent specific mass, percentage of germination and electrical conductivity at the beginning of storage and after 30;60; 90; 135 and 180 days. There was no variation in the moisture content of corn grain stored in the silo bags. Corn was classified as Type 1 during the storage period, except for grain with $18 \%$ m.c. at $35{ }^{\circ} \mathrm{C}$. There was no significant decrease in the apparent specific mass in the grain during storage. In general, the percentage of germination decreased in humid and dry corn stored and the electrical conductivity increased in the solution containing the grain, except for grain stored with $14.5 \%$ m.c. at 25 and $30{ }^{\circ} \mathrm{C}$. It is therefore possible to store corn grain in silo bags with $14.5 \%$ m.c. at $25 ; 30$ and $35{ }^{\circ} \mathrm{C}$ for 180 days, and grain with $18 \%$ m.c. at 25 and $30^{\circ} \mathrm{C}$ for 180 days.
\end{abstract}

Key words - Airtight storage. Physiological quality. Classification.

\footnotetext{
* Autor para correspondência

${ }^{1}$ Recebido para publicação em 03/08/2009; aprovado em 08/04/2010

Parte do trabalho de iniciação científica PROBIC/FAPEMIG do primeiro autor

${ }^{2}$ Programa de Pós-Graduação em Engenharia Agrícola, DEA/UFV, Viçosa-MG, Brasil, andre.costa@ufv.br

${ }_{3}^{3}$ Departamento de Engenharia Agrícola, DEA/UFV, Viçosa-MG, Brasil, lfaroni@ufv.br

${ }^{4}$ Programa de Pós-Graduação em Engenharia Agrícola, DEA/UFV, (31) 3899.1916, Viçosa-MG, Brasil, 36570-000, ernandes alencar@yahoo.com.br

${ }_{5}^{5}$ Programa de Pós-Graduação em Engenharia Agrícola, DEA/UFV, Viçosa-MG, Brasil, marta.carvalho@ufv.br

${ }^{6}$ Departamento de Engenharia Agrícola e Ambiental, DEA/UFV, Viçosa-MG, Brasil, lainegafe@yahoo.com.br
} 


\section{Introdução}

A estimativa para colheita da safra de grãos 2009/10 no Brasil é de cerca de 140 milhões de toneladas (BRASIL, 2009). Desse total, estima-se que o Brasil produza cerca de 51 milhões de toneladas de grãos de milho. Entretanto, dados da Conab (2006) demonstram que a capacidade estática de armazenagem é de cerca de 111 milhões de toneladas. Um sistema de armazenagem com déficit de capacidade estática pode acarretar, segundo Rodríguez et al. (2008), custo extra aos produtores, além de diminuir a rentabilidade dos mesmos.

O armazenamento é uma etapa de suma importância na cadeia de produção agrícola, pois tem um grande reflexo no custo e afeta diretamente a qualidade do produto que chega à mesa do consumidor. Um dos grandes problemas enfrentados pelo Brasil, em relação à produção de grãos, é o baixo índice de unidades armazenadoras localizadas nas fazendas. Isso gera uma demanda excessiva do setor de transportes (CONAB, 2006), elevando o custo do produto final.

A utilização de bolsas seladas hermeticamente para o armazenamento de grãos é uma tecnologia alternativa aos métodos tradicionais de armazenagem em fazenda e que tem merecido devida atenção e tem sido alvo de diversas pesquisas, especialmente por estar sendo utilizada em países, como no Brasil e na Argentina (FARONI et al., 2009; RODRIGUEZ et al., 2004; RODRIGUEZ et al., 2008). Essa nova técnica consiste no armazenamento de grãos em bolsas plásticas seladas hermeticamente, em que o processo respiratório dos componentes bióticos do ecossistema (grãos, fungos, insetos, etc.) consome o oxigênio $\left(\mathrm{O}_{2}\right)$ gerando dióxido de carbono $\left(\mathrm{CO}_{2}\right)$. Uma atmosfera rica em $\mathrm{CO}_{2}$ e pobre em $\mathrm{O}_{2}$ pode diminuir a capacidade de reprodução e/ou desenvolvimento de insetos e de fungos, como também a própria atividade metabólica dos grãos, favorecendo a sua conservação (JAYAS, 2000; MORENO et al., 2000; MORENO et al., 2006; QUEZADA et al., 2006), além de reduzir a taxa de oxidação do produto armazenado (VILLERS et al., 2006).

Ressalta-se que insetos e fungos são os principais responsáveis pelas perdas qualitativas e quantitativas dos grãos armazenados, sendo o desenvolvimento dos mesmos influenciados por fatores ambientais (JAYAS; WHITE, 2003; PADÍN et al., 2002). Rupollo et al. (2006) afirmam que no armazenamento hermético, o $\mathrm{CO}_{2}$ gerado e, conseqüentemente, a redução do $\mathrm{O}_{2}$ no sistema, estabiliza o processo de degradação da massa de grãos pela redução da taxa respiratória dos próprios grãos e organismos presentes. Neste contexto, é importante salientar que o manejo pós-colheita inadequado pode ocasionar rápida deterioração do produto, gerando perdas do ponto de vista nutricional e redução do valor comercial (MAGAN; ALDRED, 2007; RADÜNZ et al., 2006; REED et al., 2007).

A utilização dos silos bolsa no Brasil está, a cada ano, se tornando uma prática comum, principalmente, em propriedades agrícolas. Embora a sua difusão tenha sido em praticamente todas as regiões do País, tem-se o registro de apenas um trabalho desenvolvido por Faroni et al. (2009) e, por ter sido realizado em uma única condição climática, não retrata a realidade das demais regiões. Nesse sentido, tornase de fundamental importância a avaliação da qualidade de grãos de milho armazenados em silos bolsa em diferentes condições climáticas.

Sendo assim, objetivou-se com este trabalho avaliar a qualidade dos grãos de milho secos e úmidos armazenados hermeticamente em silos bolsa, sob diferentes temperaturas.

\section{Material e métodos}

O trabalho foi realizado no Setor de PréProcessamento e Armazenamento de Produtos Agrícolas do Departamento de Engenharia Agrícola - DEA, da Universidade Federal de Viçosa, em Viçosa-MG.

Grãos de milho (Zea mays L.), colhidos com teor de água em torno de $20,0 \%$ (b.u.) e secos até 18,0 e $14,5 \%$ (b.u.), foram acondicionados em mini-bolsas e posteriormente armazenados em câmaras climáticas com temperaturas reguladas a $25 ; 30$ e $35^{\circ} \mathrm{C}$, durante 180 dias. As mini-bolsas, com dimensões de 30 x $30 \mathrm{~cm}$, foram confeccionadas com o mesmo material utilizado na fabricação dos silos bolsa em escala comercial.

Para cada combinação de teor de água e temperatura foram utilizadas 18 mini-bolsas, totalizando 108 unidades. Em intervalos de 30 dias, até 90 dias de armazenamento, três mini-bolsas foram abertas, para cada combinação de teor de água e temperatura. As demais mini-bolsas, a partir de 90 dias, foram abertas em intervalos de 45 dias, até 180 dias de armazenamento. As seguintes análises foram realizadas:

Teor de água - Para a determinação do teor de água, foi utilizado o método de estufa com circulação forçada de ar, à temperatura de $103 \pm 1{ }^{\circ} \mathrm{C}$, durante 72 horas, em três repetições, conforme recomendações da American Society of Agricultural Engineers, método S352.2 (ASAE, 2000).

Classificação dos grãos - Os grãos de milho foram classificados de acordo com a Portaria $N^{\circ} 845$, de 08.11.1976, do Ministério da Agricultura, publicada no D.O.U. de 19.11.1976 (BRASIL, 1976). 
Massa específica aparente - Foi medida em uma balança de peso hectolítrico de $1 / 4$ de litro utilizando-se grãos limpos, ou seja, os grãos retidos na peneira de 5,0 $\mathrm{mm}$ de diâmetro, de acordo com a Portaria No 845, de 08.11.1976, do Ministério da Agricultura, publicada no D.O.U. de 19.11.1976 (BRASIL, 1976).

Percentual de germinação - Foi obtido de acordo com as Regras para Análise de Sementes (BRASIL, 1992). O teste foi conduzido com quatro repetições de 50 grãos, distribuídos sobre duas folhas de papel filtro umedecidas com água destilada na proporção de 2,5 vezes o peso do papel substrato, a $25^{\circ} \mathrm{C}$. A contagem final foi realizada aos sete dias, considerando-se as plântulas normais. Os dados foram expressos em percentagem média de germinação.

Condutividade elétrica - A condutividade elétrica da solução contendo os grãos de milho foi feita utilizandose o sistema de copo ou massa (bulk system), conforme descrito por Vieira et al. (2001), tendo como finalidade avaliar o aumento da permeabilidade da membrana, à medida que o grão se deteriora. Os testes foram realizados em três repetições, com 50 grãos, para cada combinação de teor de água e temperatura. Os grãos foram pesados e colocados em copos de plástico de $200 \mathrm{~mL}$, aos quais foram adicionados $75 \mathrm{~mL}$ de água destilada. Em seguida, os copos foram colocados em uma câmara climática, em temperatura de $25^{\circ} \mathrm{C}$, durante $24 \mathrm{~h}$. Imediatamente após este período, os copos foram retirados da câmara para medições da condutividade elétrica da solução que continha os grãos. As leituras foram feitas em medidor de condutividade elétrica da marca Tecnopon, modelo CA-150. O valor da condutividade elétrica $\left(\mu \mathrm{S} \mathrm{cm}^{-1}\right)$ fornecido pelo aparelho foi dividido pela massa dos grãos (g), obtendo-se valor expresso em $\mu \mathrm{S} \mathrm{cm}^{-1} \mathrm{~g}^{-1}$.

Delineamento experimental - Foi utilizado o delineamento inteiramente casualizado, em esquema de parcelas subsubdivididas, tendo nas parcelas teor de água dos grãos, nas subparcelas a temperatura de armazenamento e nas subsubparcelas os períodos de armazenamento, em três repetições. Cada parcela foi constituída de 54 mini-bolsas, cada subparcela foi 36 minibolsas e cada subsubparcela por 18 mini-bolsas. Para a variável teor de água, utilizou-se estatística descritiva. Realizou-se análise de variância, a 5\% de probabilidade, para as variáveis massa específica aparente, percentual de germinação e condutividade elétrica, utilizando-se o software Saeg 9.0. Para a variável condutividade elétrica, realizou-se análise de regressão, sendo os gráficos plotados com software Microsoft Excel 2007.

\section{Resultados e discussão}

$\mathrm{Na}$ Tabela 1, encontram-se os valores médios de teor de água dos grãos de milho armazenados com 14,5 e $18,0 \%$ (b.u.) em silos tipo bolsa, nas temperaturas de 25; 30 e $35{ }^{\circ} \mathrm{C}$. Em geral, verifica-se que não houve aumento do teor de água dos grãos de milho armazenados nos silos tipo bolsa, independentemente da temperatura. Esse comportamento pode ser explicado pelo fato de que a hermeticidade dificulta e/ou impede a atividade metabólica tanto dos grãos quanto dos microrganismos (JAYAS, 2000; MORENO et al., 2006).

$\mathrm{Na}$ Tabela 2, encontram-se os Tipos Finais referentes à classificação dos grãos de milho armazenados hermeticamente em silos bolsa, com teores de água de 14,5 e $18,0 \%$ (b.u.) nas temperaturas de $25 ; 30$ e $35^{\circ} \mathrm{C}$. Esses valores foram obtidos a partir dos laudos de classificação emitidos pelo Instituto Mineiro de Agropecuária - IMA. Verifica-se que, em geral, os grãos de milho úmidos e secos foram classificados como Tipo 1 ao longo do período de armazenamento. Os grãos armazenados com 18,0\% (b.u.) de teor de água na temperatura de $35^{\circ} \mathrm{C}$ foram os que apresentaram maior perda de qualidade a partir dos

Tabela 1 - Valores médios de teor de água dos grãos de milho armazenados com 14,5 e 18,0\% (b.u.) em silos tipo bolsa, nas temperaturas de $25 ; 30$ e $35^{\circ} \mathrm{C}$, durante 180 dias

\begin{tabular}{|c|c|c|c|c|c|c|c|}
\hline \multirow{2}{*}{ Temperatura $\left({ }^{\circ} \mathrm{C}\right)$} & \multicolumn{6}{|c|}{ Período de armazenamento (dias) } & \multirow{2}{*}{ Média \pm DP* } \\
\hline & 0 & 30 & 60 & 90 & 135 & 180 & \\
\hline \multirow{2}{*}{25} & 14,5 & 14,7 & 14,6 & 15,0 & 15,0 & 14,3 & $14,7 \pm 0,28$ \\
\hline & 18,0 & 18,0 & 18,0 & 18,0 & 19,0 & 18,3 & $18,2 \pm 0,40$ \\
\hline \multirow{2}{*}{30} & 14,5 & 14,6 & 14,7 & 15,0 & 15,3 & 14,7 & $14,8 \pm 0,30$ \\
\hline & 18,0 & 17,6 & 19,0 & 19,0 & 19,0 & 19,3 & $18,7 \pm 0,68$ \\
\hline \multirow{2}{*}{35} & 14,5 & 14,6 & 15,0 & 14,7 & 15,2 & 14,5 & $14,8 \pm 0,29$ \\
\hline & 18,0 & 18,7 & 16,5 & 18,0 & 19,0 & 18,0 & $18,0 \pm 0,86$ \\
\hline
\end{tabular}

* DP - Desvio padrão 
Tabela 2 - Classificação de grãos de milho com teores de água de 14,5 e 18,0\% (b.u.) armazenados em silos tipo bolsa, nas temperaturas de $25 ; 30$ e $35^{\circ} \mathrm{C}$

\begin{tabular}{ccccccc}
\hline & \multicolumn{6}{c}{ Classificação - Tipo Final } \\
\cline { 2 - 7 } Dias & \multicolumn{7}{c}{ Teor de água (\%) (b.u.) } \\
\cline { 2 - 7 } & \multicolumn{7}{c}{ Temperatura $\left({ }^{\circ} \mathrm{C}\right)$} \\
& \multicolumn{7}{c}{14,5} & 35 & 25 & 30 & 35 \\
\hline 0 & 1 & 1 & 1 & 1 & 1 & 1 \\
30 & 1 & 1 & 1 & 1 & 1 & 1 \\
60 & 1 & 1 & 1 & 1 & 1 & 1 \\
90 & 1 & 1 & 1 & 1 & 1 & 3 \\
135 & 1 & 1 & 1 & 1 & 1 & 1 \\
180 & 1 & 1 & 3 & 1 & 1 & 3 \\
\hline
\end{tabular}

parâmetros dos Laudos de Classificação (Tabela 2). O que contribuiu para esse comportamento foi o aumento dos grãos ardidos e avariados.

Na Figura 1 são apresentados os valores médios de massa específica aparente dos grãos de milho úmidos e secos armazenados em silos tipo bolsa, nas temperaturas de $25 ; 30$ e $35{ }^{\circ} \mathrm{C}$. Apesar de ter ocorrido decréscimo da massa específica aparente dos grãos de milho armazenados nos silos bolsa, essa variação não foi significativa (Tabela 3).

Bartosik e Rodriguez (1999) avaliaram a variação da massa específica aparente em grãos de trigo (Triticum aestivum L.) armazenados com 12,5 e 16,4\% (b.u.) de teor de água em silos bolsa. Esses autores também verificaram decréscimo desse parâmetro ao longo de período de armazenamento, sendo esse comportamento mais acentuado nos grãos com maior teor de água.
A variação da massa específica aparente de grãos de milho armazenados hermeticamente em silos bolsa foi estudada por Rodríguez et al. (2004), que verificaram acréscimo de $0,7 \%$ e decréscimo de $2,5 \%$ da massa específica aparente após 153 dias de armazenamento para o produto com 14,8 e 19,5\% (b.u.) de teor de água, respectivamente.

De acordo com os resultados da análise de variância (Tabela 3), houve diferença significativa do percentual de germinação dos grãos de milho armazenados em silos bolsa devido à interação tripla entre teor de água, temperatura e período de armazenamento.

Os valores médios de percentual de germinação dos grãos de milho armazenados com diferentes teores de água para cada temperatura durante o armazenamento encontram-se na Figura 2. Em geral, ocorreu decréscimo do percentual de germinação dos
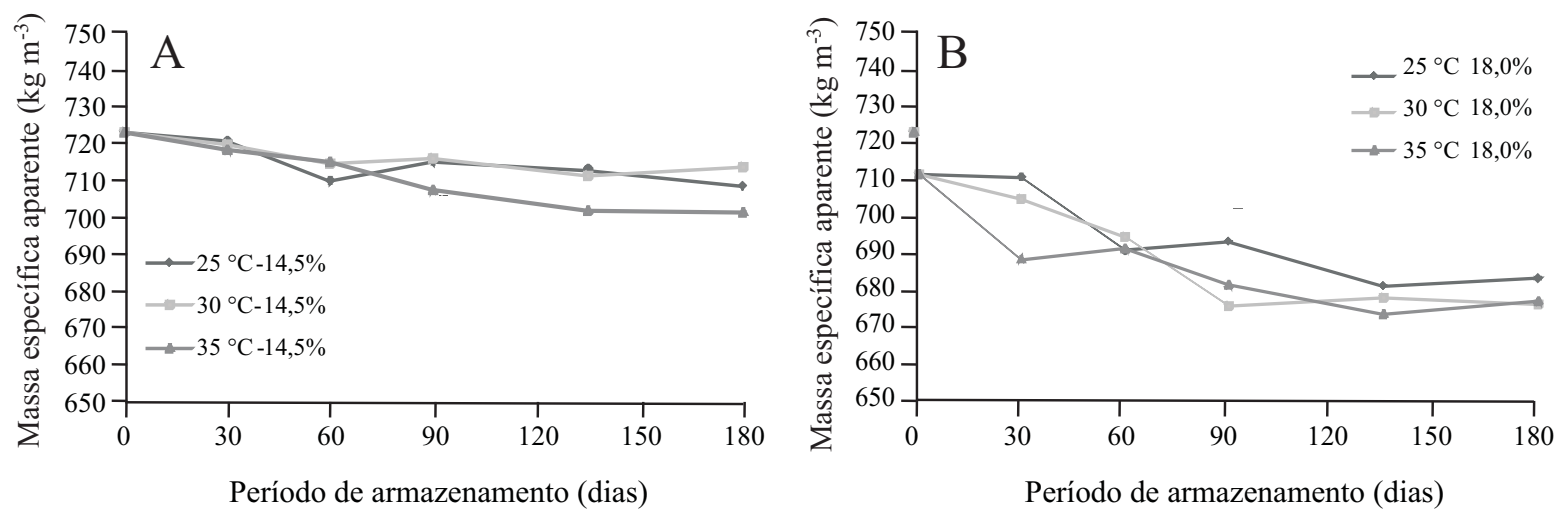

Figura 1 - Valores médios da massa específica aparente dos grãos de milho com teores de água de 14,5 (A) e 18,0\% (B) (b.u.) armazenados em silos tipo bolsa, nas temperaturas de $25 ; 30$ e $35^{\circ} \mathrm{C}$ 
Tabela 3 - Resumo da análise de variância das variáveis massa específica aparente (MEA), percentual de germinação (PG) e condutividade elétrica (CE) dos grãos de milho armazenados em silos bolsa, com teores de água de 14,5 e 18,0\% b.u. nas temperaturas de 25,30 e $35^{\circ} \mathrm{C}$

\begin{tabular}{lcccc}
\hline \multirow{2}{*}{ Fontes de Variação } & g.L. & \multicolumn{3}{c}{ Quadrados médios } \\
\cline { 3 - 5 } & & $11.984,2^{\text {ns }}$ & PG & CE \\
\hline Teor de água (TA) & 1 & $2.123 .858,0$ & $22,173,9^{*}$ & $4.215,4^{*}$ \\
Resíduo (a) & 4 & $7.331 .096,0^{\text {ns }}$ & $11.791,8^{*}$ & 6,3 \\
Temperatura (T) & 2 & $3.143781,0^{\text {ns }}$ & $1.004,9^{*}$ & $876,7^{*}$ \\
T x TA & 2 & $3.712 .389,0$ & 14,2 & $28,2^{*}$ \\
Resíduo (b) & 8 & $1.723 .538^{\text {ns }}$ & $12.080,1^{*}$ & 8,0 \\
Período de armazenamento (P) & 5 & $3.593 .084^{\text {ns }}$ & $859,4^{*}$ & $1.412,0^{*}$ \\
T x P & 10 & $5.086 .955^{\text {ns }}$ & $3.122,9^{*}$ & $101,5^{*}$ \\
TA x P & 5 & $4.460 .992^{\text {ns }}$ & $2.638,9^{*}$ & $319,7^{*}$ \\
T x P x TA & 10 & 4.457 .255 & 28,9 & $37,4^{*}$ \\
Resíduo (c) & 60 & 688,6 & 9,7 & 6,4 \\
\hline CV (\%) & & & 9,1 \\
\hline
\end{tabular}

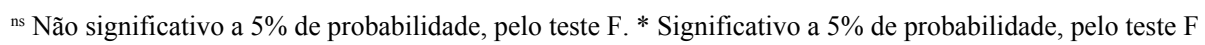

grãos de milho armazenados úmidos e secos, exceto para os armazenados com $14,5 \%$ (b.u.) e nas temperaturas de 25 e $30{ }^{\circ} \mathrm{C}$ (Figura 2A), sendo observados valores médios acima de $85 \%$ após 180 dias de armazenamento. Para os grãos armazenados com 14,5\% (b.u.) de teor de água a $35{ }^{\circ} \mathrm{C}$ verifica-se percentual de germinação igual a zero após 135 dias de armazenamento.

Por outro lado, verifica-se redução mais acentuada do percentual de germinação dos grãos armazenados com teor de água de $18,0 \%$ (b.u.), sendo esse comportamento acelerado à medida que se têm maiores temperaturas (Figura 2B). Obteve-se percentual de germinação igual a zero para os grãos úmidos armazenados nas temperaturas de $25 ; 30$ e 35 ${ }^{\circ} \mathrm{C}$ após 135; 90 e 30 dias, respectivamente.

Vários pesquisadores estudaram a influência de fatores qualitativos relacionados com a germinação de grãos durante o armazenamento hermético e não hermético. Karunakaran et al. (2001) armazenaram trigo (Triticum aestivum L.) com teores de água na faixa entre 15,0 e $19,0 \%$ (b.u.) em diferentes temperaturas, em condições não herméticas, com o intuito de verificar o período de armazenagem seguro e utilizaram percentual de germinação como padrão qualitativo. Esses autores obtiveram períodos de armazenamento seguros equivalentes a 15; 7 e 5 dias para os grãos armazenados
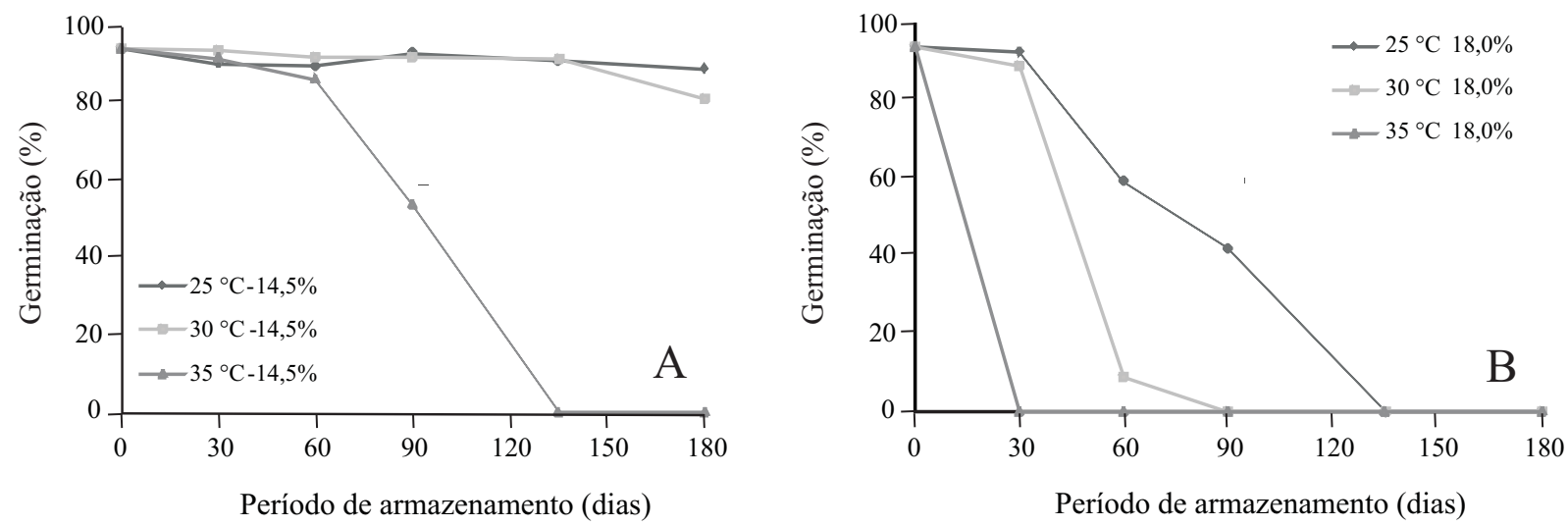

Figura 2 - Valores médios de percentual de germinação dos grãos de milho com teores de água de 14,5 (A) e 18,0\% (B) (b.u.) armazenados em silos tipo bolsa, nas temperaturas de $25 ; 30$ e $35^{\circ} \mathrm{C}$ 
com teor de água de $17,0 \%$ (b.u.), nas temperaturas de 25 ; 30 e $35^{\circ} \mathrm{C}$, respectivamente.

Vários pesquisadores estudaram a influência de fatores qualitativos relacionados com a germinação de grãos durante o armazenamento hermético e não hermético. Karunakaran et al. (2001) armazenaram trigo (Triticum aestivum L.) com teores de água na faixa entre 15,0 e $19,0 \%$ (b.u.) em diferentes temperaturas, em condições não herméticas, com o intuito de verificar o período de armazenagem seguro e utilizaram percentual de germinação como padrão qualitativo. Esses autores obtiveram períodos de armazenamento seguros equivalentes a 15; 7 e 5 dias para os grãos armazenados com teor de água de $17,0 \%$ (b.u.), nas temperaturas de $25 ; 30$ e $35^{\circ} \mathrm{C}$, respectivamente.

Em se tratando de armazenamento hermético, Guberac et al. (2003) avaliaram o comportamento da qualidade fisiológica de sementes de trigo, aveia (Avena sativa L.) e milho (Zea mays L.) armazenadas hermeticamente em containeres de vidro durante 5 anos, com temperatura e umidade relativa do ar controladas. Os autores verificaram que tanto o trigo quanto a aveia não apresentaram variação significativa do percentual de germinação, mas os grãos de milho apresentaram decréscimo significativo após 5 anos de armazenamento. O percentual de germinação em grãos de trigo armazenados hermeticamente em silos bolsa com 12,5 e $16,4 \%$ (b.u.) de teor de água foi avaliado por Bartosik et al. (1999), que observaram efeito altamente significativo do teor inicial de água. Esses autores observaram que os grãos de trigo secos perderam $7 \%$ do poder germinativo após 150 dias de armazenamento. Por outro lado, o produto armazenado com $16,4 \%$ (b.u.) de teor de água perdeu $69,0 \%$ do poder germinativo após o mesmo período.
$\mathrm{O}$ efeito da armazenagem hermética no percentual de germinação de grãos também foi estudado por Rodríguez et al. (2004), os quais verificaram que os grãos de milho após serem armazenados em silos bolsa com 14,8 e 19,5\% (b.u.) de teor de água; obtiveram um decréscimo na germinação em ambas as condições, após 153 dias, sendo esse comportamento mais acentuado nos grãos com menor teor de água. Nos grãos armazenados com 14,8\% (b.u.) de teor de água, o percentual de germinação decresceu de $68,9 \%$ para $57,3 \%$. Por outro lado, observaram ainda decréscimo de $89,0 \%$ para $84,3 \%$ nos grãos armazenados com $19,5 \%$ (b.u.) de teor de água. O menor decréscimo do percentual de germinação nos grãos úmidos foi explicado pelo fato do produto ter sido acondicionado no silo numa época de temperatura inferior a de acondicionamento do produto seco.

Com relação à variável condutividade elétrica da solução que continha os grãos de milho armazenados em silos bolsa, obteve-se variação significativa (Tabela 3) pela interação teor de água, temperatura e período de armazenamento.

Apresentam-se, na Figura 3, as curvas de regressão da condutividade elétrica dos grãos armazenados hermeticamente com diferentes teores de água, em três temperaturas, durante 180 dias. Na Tabela 4, encontramse as curvas de regressão ajustadas e os seus respectivos coeficientesdedeterminação, querelacionamcondutividade elétrica referente aos grãos armazenados úmidos e secos para cada temperatura de armazenamento.

Observa-se que, independentemente do teor de água, a condutividade elétrica da solução aumentou ao longo do armazenamento (Figura 3). Os grãos armazenados com teor de água de $14,5 \%$ (b.u.) apresentaram condutividade elétrica
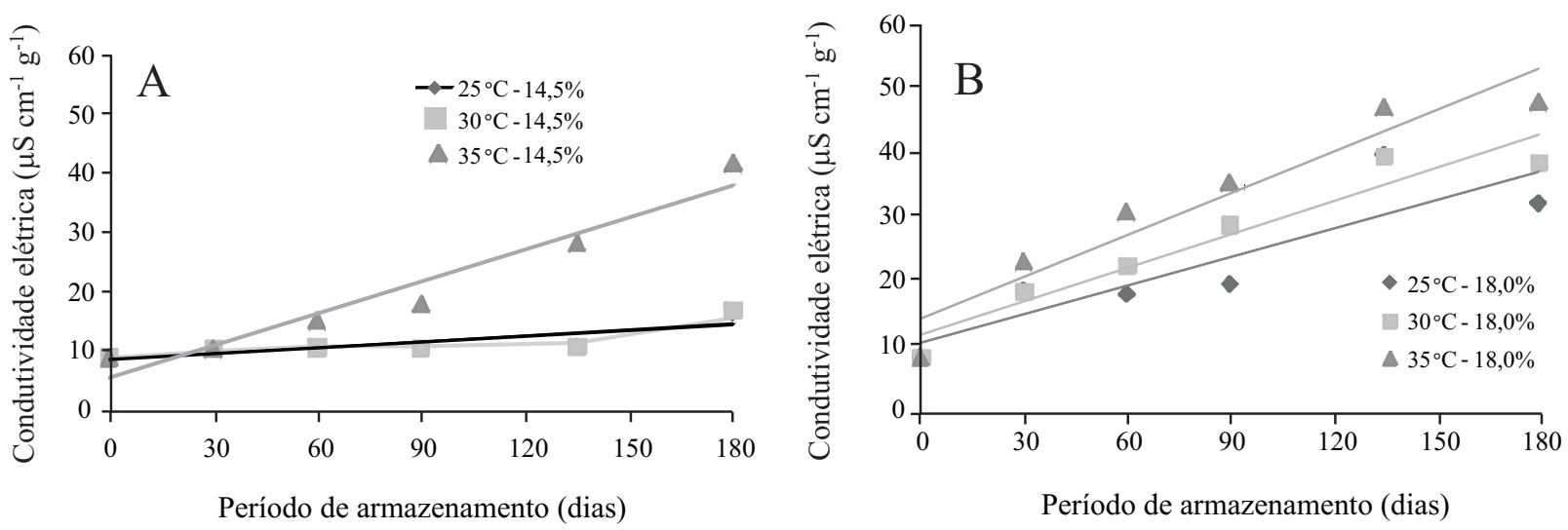

Figura 3 - Curvas de regressão da condutividade elétrica $\left(\mu \mathrm{S} \mathrm{cm}^{-1} \mathrm{~g}^{-1}\right)$ da solução que continha os grãos de milho com teores de água de 14,5 (A) e $18,0 \%$ (B) (b.u.) armazenados em silos tipo bolsa, nas temperaturas de $25 ; 30$ e $35^{\circ} \mathrm{C}$ 
Tabela 4 - Equações de regressão ajustadas para da condutividade elétrica ( $\mu \mathrm{S} \mathrm{cm}-1 \mathrm{~g}-1)$ da solução que continha os grãos de milho com teores de água de 14,5 e $18,0 \%$ (b.u.) armazenados em silos bolsa, nas temperaturas de $25 ; 30$ e $35^{\circ} \mathrm{C}$

\begin{tabular}{ccrc}
\hline Temperatura $\left({ }^{\circ} \mathrm{C}\right)$ & Teor de água $(\%)$ & Equações ajustadas & $\mathrm{R}^{2}$ \\
\hline \multirow{2}{*}{25} & 14,5 & $\hat{\mathrm{y}}=8,95+0,0314 * \mathrm{X}$ & 0,83 \\
& 18,0 & $\hat{\mathrm{y}}=10,66+0,1477 * \mathrm{X}$ & 0,77 \\
\multirow{2}{*}{30} & 14,5 & $\hat{\mathrm{y}}=8,75+0,0343 * \mathrm{X}$ & 0,67 \\
& 18,0 & $\hat{\mathrm{y}}=11,84+0,1730^{* * \mathrm{X}}$ & 0,93 \\
\multirow{2}{*}{35} & 14,5 & $\hat{\mathrm{y}}=5,67+0,1812^{* * \mathrm{X}}$ & 0,94 \\
& 18,0 & $\hat{\mathrm{y}}=14,46+0,2160^{* * \mathrm{X}}$ & 0,92 \\
\hline
\end{tabular}

*Significativo a $5 \%$ de probabilidade. ${ }^{* *}$ Significativo a $1 \%$ de probabilidade.

mais acentuada na temperatura de $35^{\circ} \mathrm{C}$ (Figura 3A). Por outro lado, os grãos armazenados com $18,0 \%$ (b.u.) de teor de água apresentaram condutividade elétrica mais elevada que aqueles armazenados secos (Figura 3B), o que indica que ocorreu um processo de deterioração da membrana e parede celular mais acelerado. Verifica-se ainda, para os grãos úmidos, que os maiores valores de condutividade elétrica foram correspondentes à temperatura de $35{ }^{\circ} \mathrm{C}$.

O comportamento da condutividade elétrica da solução que continha os grãos de milho armazenados hermeticamente está de acordo com a variação do percentual de germinação apresentada na Figura 2. Grãos com maiores valores de condutividade elétrica caracterizamse por apresentarem maiores taxas de degradação da membrana celular e conseqüentemente menor vigor (VIEIRA; KRZYZANOWSKI, 1999). Vale ressaltar que o acréscimo da condutividade é mais acentuado à medida que se eleva a temperatura de armazenamento dos grãos (FARONI et al., 2005).

De acordo com Heslehurst (1988), a leitura da condutividade elétrica da solução que contém as sementes pode ser utilizada para avaliar o vigor, visto que o valor da condutividade está relacionado com a quantidade de íons lixiviados na solução, a qual está diretamente associada à integridade das membranas celulares; membranas mal estruturadas e células danificadas estão, geralmente, associadas ao processo de deterioração de sementes e, portanto, a sementes de baixo vigor. Em feijão (Phaseolus vulgaris L.), segundo Lin (1990), perdas na geminação e no vigor de sementes envelhecidas estão correlacionadas com o aumento da lixiviação eletrolítica, que aumenta com a diminuição dos fosfolipídios da membrana. Os menores valores, correspondentes à menor liberação de íons, indicam alto potencial fisiológico (maior vigor), revelando menor intensidade de desorganização dos sistemas de membranas das células (VIEIRA et al., 2002).

\section{Conclusões}

1. Para fins de comercialização de grãos de milho, foi possível armazenar em silos bolsa, por 180 dias, grãos com teor de água de $14,5 \%$ (b.u.) nas temperaturas de $25 ; 30$ e $35^{\circ} \mathrm{C}$, e grãos com teor de água de $18,0 \%$ (b.u.) nas temperaturas de 25 e $30^{\circ} \mathrm{C}$, sem alterar o tipo final referente à classificação do produto. Os grãos com teor de água de $18,0 \%$ (b.u.) e armazenados por até 60 dias em silos bolsa, na temperatura de $35^{\circ} \mathrm{C}$, não apresentaram alteração no tipo final referente à classificação.

2. Grãos de milho armazenados com 14,5\% (b.u.) de teor de água em silos bolsa nas temperaturas de $25 \mathrm{e}$ $30{ }^{\circ} \mathrm{C}$ mantiveram qualidade fisiológica satisfatória por 180 dias. Os grãos armazenados com teor de água de $18,0 \%$ (b.u.) apresentaram redução mais acentuada da qualidade fisiológica ao de 180 dias à medida que se elevou a temperatura.

\section{Referências}

AMERICAN SOCIETY OF AGRICUTURAL ENGINEERS (ASAE). Moisture measurement - Unground grain and seeds. ASAE, 2000. p. 563.

BARTOSIK, R. E.; RODRÍGUEZ, J. C. Evaluación de una técnica de almacenaje de granos a $\mathbf{1 2 . 5 \%}$ de humedad en bolsas plásticas - Sistema silobag. Informe INTA-IPESA, 1999. 10 p.

BRASIL. Mistério da Agricultura, Pecuária e Abastecimento. Portaria $n^{\circ} 845$ de 08.11.1976. Especificações para padronização, classificação e comercialização interna do milho. Diário Oficial, Brasília,1976.

BRASIL. Regras para Análise de Sementes. Brasília: Ministério da Agricultura, Pecuária e Abastecimento, 1992. 365 p.

BRASIL. Acompanhamento da safra brasileira 2007/2008 de grãos. Disponível em: < http://www.conab.gov.br/ conabweb/download/safra/2graos_09.10.pdf> Acesso em: 01 de nov. 2009. 
COMPANHIA NACIONAL DE ABASTECIMENTO (CONAB). Capacidade estática de armazenagem cadastrada resumo total Brasil. Disponível em: $<\mathrm{http}$ ://www.conab.gov. br/ projinfogerenciais/resumo-capac-popup.asp $>$ Acesso em: 30 abr. 2006.

FARONI, L. R. A. et al. Avaliação qualitativa e quantitativa do milho em diferentes condições de armazenamento. Engenharia na Agricultura, v. 13, n. 03, 193-201, 2005.

FARONI, L. R. A. et al. Armazenamento de soja em silos tipo bolsa. Engenharia Agrícola, v. 29, n. 01, p. 91-100, 2009.

GUBERAC, V. et al. Hermetically sealed storage of cereal seeds and its influence on vigour and germination. Journal Agronomy \& Crop Science, v. 189, n. 01, p. 54-56, 2003.

HESLEHURST, M. R. Quantifying initial quality and vigour of wheat seeds using regression analysis of conductivity and germination data from aged seeds. Seed Science and Technology, v. 16, n. 01, p. 75-85., 1988.

JAYAS, D. S. Controlling insects in stored grain using modified atmospheres of elevated carbon dioxide. L'Actualité chimique canadienne, v. 52, n. 07, p. 10-24, 2000.

JAYAS, D. S.; WHITE, N. D. G. Storage and drying of grain in Canada: low cost approaches. Food Control, v. 14, n. 04, p. 255-261, 2003.

KARUNAKARAN, C. et al. Safe storage time of high moisture wheat. Journal of Stored Products Research, v. 37, n. 03, p. 303-312, 2001.

LIN, S. S. Alterações na lixiviação eletrolítica, germinação e vigor da semente de feijão envelhecida sob alta umidade relativa do ar e alta temperatura. Revista Brasileira Fisiologia Vegetal, v. 02, n. 02, p. 1-6, 1990.

MAGAN, N.; ALDRED, D. Post-harvest control strategies: Minimizing mycotoxins in the food chain. International Journal of Food Microbiology, v. 119, n. 01/02, p.131-139, 2007.

MORENO, M. E.; JIMENEZ, A. S.; VAZQUEZ, M. E. Effect of Sitophilus zeamais and Aspergillus chevalieri on the oxygen level in maize stored hemetically. Journal of Stored Product Research, v. 36, n. 01, p. 25-36, 2000.

MORENO, M. E.; JIMENEZ, A. S.; VAZQUEZ, M. E. Hermetic storage system preventing the proliferation of Prostephanus truncatus Horn and storage fungi in maize with different moisture contents. Postharvest Biology and Technology, v. 39, n. 03, p. 321-326, 2006.
PADÍN, S.; BELLO, G. D.; FABRIZIO, M. Grain loss caused by Tribolium castaneum, Sitophilus oryzae and Acanthoscelides obtectus in stored durum wheat and beans treated with Beauveria bassiana. Journal of Stored Products Reseach, v. 38, n. 01, p. 69-74, 2002.

QUEZADA, M. Y. et al. Hermetic storage system preventing the proliferation of Prostephanus truncatus Horn and storage fungi in maize with different moisture contents. Postharvest Biology and Technology, v. 39, n. 03, p. 321-326, 2006.

RADÜNZ, L. L. R. et al. Influência do método de armazenamento na qualidade física e biológica de grãos de milho. Revista Brasileira de Armazenamento, v. 31, n. 02, p. 136-143, 2006.

REED, C. et al. Response of storage molds to different initial moisture contents of maize (corn) stored at $25{ }^{\circ} \mathrm{C}$, and effect on respiration rate and nutrient composition. Journal of Stored Products Research, v. 43, n. 04, p. 443-458, 2007.

RODRÍGUEZ J. C. et al. IP short term storage of Argentine cereals in silobags to prevent spoilage and insects. In: INTERNATIONAL QUALITY GRAINS CONFERENCE, 2004, Indianapolis, Proceedings... Indianapolis: US Quality Grains Research Consortium, 2004. p. 1-15.

RODRÍGUEZ, J. C. et al. Almacenaje de granos en bolsas plásticas: sistema silobag. Disponível em: $<\mathrm{http} / / \mathrm{www}$.engormix. com/S_articles_view.asp?art=802> Acesso em: $10 \mathrm{fev} .2008$.

RUPOLLO, G. et al. Efeito da umidade e do período de armazenamento hermético na contaminação natural por fungos e a produção de micotoxinas em grãos de aveia. Ciência e Agrotecnologia, v. 30, n. 01, p. 118-125, 2006.

VIEIRA, R. D. et al. Electrical conductivity of soybean seeds after storage in several environments. Seed Science and Technology, v. 29, n. 03, p. 599-608, 2001.

VIEIRA, R. D. et al. Condutividade elétrica e teor de água inicial das sementes de soja. Pesquisa Agropecuária Brasileira, v. 37, n. 09 , p. $1333-1338,2002$.

VIEIRA, R. D.; KRZYZANOWSKI, F.C. Teste de condutividade elétrica. In: KRZYZANOWSKI, F. C. H.; VIEIRA, R. D.; FRANCA NETO, J. B. Vigor de sementes: conceitos e testes. Londrina: ABRATES, 1999. p. 4-20.

VILLERS, P.; BRUIN, T.; NAVARRO, S. Safe storage of grain in the tropics: A comparison of hermetic storage in flexible silos versus rigid metal or concrete silos. In: WEST, A.; BROWN, J. Feed Technology Update. Honolulu: Linx Publishing, 2006, p. 17-22. 